\title{
Association of dyslipidemia in second trimester of pregnancy with preeclampsia
}

\section{Kanmani K., Sudha Subramanian*} Department of Obstetrics and Gynecology, Institute of Social Obstetrics and Kasthuriba Gandhi Hospital for Women,
Chennai, India

Received: 26 December 2017

Accepted: 12 January 2018

\section{*Correspondence:}

Dr. Sudha Subramanian,

E-mail: sudhammc@gmail.com

Copyright: () the author(s), publisher and licensee Medip Academy. This is an open-access article distributed under the terms of the Creative Commons Attribution Non-Commercial License, which permits unrestricted non-commercial use, distribution, and reproduction in any medium, provided the original work is properly cited.

\section{ABSTRACT}

Background: The study aimed to determine whether dyslipidemia in the second trimester of pregnancy is associated with pre-eclampsia and to investigate and compare the levels of serum lipids among preeclampsia and normal pregnant women.

Methods: This prospective cohort study was done between March 2016 to February 2017. Fasting lipid profile was taken for about 200 selected antenatal women between 18-20 weeks of gestation. The patients who developed preeclampsia were grouped as preeclampsia group and the rest of the patients were grouped as normal group. The maternal characteristics compared between two groups were age, parity, BMI and socioeconomic class according to modified Kuppuswamy scale.

Results: There is statistical significance among the two groups with respect to BMI and parity whereas no significance with age distribution. Mean total cholesterol in Preeclampsia was $240.24 \pm 46.63 \mathrm{mg} / \mathrm{dl}$ and normal pregnancy was $186.10 \pm 28.02 \mathrm{mg} / \mathrm{dl}$. Mean HDL in preeclampsia was $47.49 \pm 4.40 \mathrm{mg} / \mathrm{dl}$ and normal pregnancy was $52.11 \pm 8.918 \mathrm{mg} / \mathrm{dl}$. Mean LDL in preeclampsia was $140.43 \pm 36.92 \mathrm{mg} / \mathrm{dl}$ and normal pregnancy was $94.6 \pm 24.5$ $\mathrm{mg} / \mathrm{dl}$. Mean VLDL in preeclampsia was $64.48 \pm 15.76 \mathrm{mg} / \mathrm{dl}$ and in normal pregnancy was $33.54 \pm 9.38 \mathrm{mg} / \mathrm{dl}$, Mean Triglycerides in preeclampsia was $291.95 \pm 82.33 \mathrm{mg} / \mathrm{dl}$ and normal pregnancy was $166.78 \pm 48.83 \mathrm{mg} / \mathrm{dl}$. Total cholesterol, Low density lipoprotein, very low-density lipoprotein, triglycerides were increased in preeclampsia when compared to normal pregnancy, which is statistically significant.

Conclusions: Detecting dyslipidemia before 20 weeks of gestation helps to recognise pregnancies at high risk for preeclampsia and to detect and treat the disease earlier for a better maternal and perinatal outcome.

Keywords: Preeclampsia, Triglycerides, Total cholesterol

\section{INTRODUCTION}

Pre-eclampsia is a pregnancy-specific condition with a multifactorial etiology associated with proteinuria and hypertension. ${ }^{1,2}$ It is one of the common causes of maternal and perinatal morbidity and mortality.

Berg and colleagues stated that around $50 \%$ of these preeclampsia related deaths are preventable. ${ }^{3}$
The exact etiology of preeclampsia is not known. But there are risk factors predisposing to development of preeclampsia. Genetic factors include family history of preeclampsia. $^{4}$

Obstetric factors include primiparity, previous history of pre- eclampsia, new paternity, multiple pregnancy, hydrops fetalis with large placenta, hydatidiform mole, triploidy. 
Medical factors include chronic hypertension, diabetes, renal disease, antiphospholipid antibody syndrome, inherited thrombophilias, connective tissue disorders, hyperhomocysteinemia.

Plasma lipids and lipoproteins increase during pregnancy. The mechanism for pregnancy-induced changes in lipids is not completely understood, but appears to be partly caused by elevated oestrogen, progesterone and human placental lactogen. ${ }^{5,6}$ Lipid levels in women with Preterm labour or pre-eclampsia are reported to be higher than those in healthy pregnant women. ${ }^{7-9}$

Lipid levels in early pregnancy can be a good predictor of development of pre-eclampsia in patients. Dyslipidemia in early pregnancy leads to more oxidative stress by the formation of lipid peroxides and reactive oxygen species, thus predisposing to the development of preeclampsia. ${ }^{10,11}$

The pathology of this multi system disorder should be considered as two staged process. ${ }^{12}$

\section{Abnormal placentation}

In pre-eclampsia, the primary wave of trophoblastic invasion is partly impaired, and the second wave fails to occur. This results in reduced uteroplacental blood flow, which worsens as the pregnancy advances. In addition, the arteries remain very sensitive to vasomotor stimuli. These changes are not specific to pre-eclampsia but also occurs in IUGR without pre-eclampsia. ${ }^{13}$

The myointimal cell proliferation, endothelial damage with medial necrosis forms the early pre-eclamptic changes. These findings with lipid laden cells infiltration is termed as 'atherosis'. A similar pathology is seen in atherosclerosis. ${ }^{14}$ Since abnormal lipid profiles are associated with atherosclerosis, the hypothesis of dyslipidemia for development of pre-eclampsia is biologically plausible. ${ }^{15}$

\section{Maternal systemic reaction}

Maternal systemic reaction such as vasospasm impairs perfusion in narrow spiral arteries leading to a hypoxic environment inducing systemic inflammatory response. ${ }^{16}$

Dysregulation or loss of maternal immune tolerance to paternally derived placental debris leads to activation of leucocytes and release of cytokine resulting in endothelial injury. ${ }^{17}$

In pre-eclampsia, due to the endothelial dysfunction, there is a reduction in prostocyclin and nitric oxide, which are vasodilators and an increase in endothelin and thromboxane which are vasoconstrictors. ${ }^{18}$ Besides this, loss of vascular insensitivity to pressor agents results in vasospasm and thereby increases vascular resistance and blood pressure.
Endothelial dysfunction leads to release of cytokines such as TNF- alpha and interleukins which may contribute to oxidative stress characterised by increased ROS (Reactive Oxygen Species) and free radicals that leads to formation of self propagating lipid peroxides.

The increased levels of lipid peroxides and decreased antioxidant activity in pre-eclampsia have raised the possibility that markers of oxidative stress may predict pre-eclampsia.

As blood lipids like triglycerides and free fatty acids and lipoprotein belong to the variety of pro-oxidants or potentiators of pro-oxidants, they can be used as markers of pre-eclampsia.

Endothelial dysfunction will lead to activation of platelets and coagulation system by the release of tissue factors from endothelium. This results in widespread DIC ranging from subclinical to frank DIC.

Aim of the present study was to evaluate whether abnormal lipid profile in the second trimester of pregnancy is associated with the occurrence of preeclampsia.

\section{METHODS}

It was a prospective cohort study. This study was conducted in the Antenatal clinic, Institute of Social Obstetrics and Kasthuriba Gandhi Hospital for women, Chennai, India for the period of one year from March 2016 to February 2017.

\section{Inclusion criteria}

- $\quad$ Pregnant women with singleton pregnancy

- With LMP and USG confirmed pregnancy between 18-20 weeks of gestation.

\section{Exclusion criteria}

- Diabetes mellitus

- Chronic hypertension

- Renaldisorder

- Hypothyroidism

- Family/personalhistory of dyslipidemia

- Previous history of miscarria.

- Ultrasound proved congenital anamolies

- PCOS

A total of 200 antenatal patients who attended the antenatal clinic of Institute of Social Obstetrics and Kasthuriba Gandhi Hospital for women were selected based on the inclusion and exclusion criteria after obtaining their informed consent.

All selected women were subjected to a detailed history taking comprising of age, parity, prepregnant body 
weight, medication history, family history, medical history, detailed obstetric history. Then they were subjected to clinical examination and routine laboratory investigations were carried out on the first day.

Fasting blood samples $(4 \mathrm{ml})$ were collected from these patients the next day and subjected to lipid profile analysis. Total cholesterol and triglycerides were estimated by enzymatic methods HDL-Cholesterol (HDL-C) was estimated by phosphotungstic acid precipitation followed by enzymatic analysis in supernatant fraction and LDL-Cholesterol (LDL-C) was determined by using Friedewald's equation.

Total Cholesterol, HDL, TGL levels were estimated and the levels of LDL and VLDL were calculated indirectly.

These patients were regularly followed up in the antenatal op till their delivery once in every two weeks and a thorough clinical examination was carried with special focus on blood pressure and urine albumin. All the details were entered.

Definitions used for diagnosis of preeclampsia was according to the International Society for the study of Hypertension in pregnancy (ISSHP). Hypertension is defined as a systolic blood pressure $>140 \mathrm{~mm} \mathrm{Hg}$ or a diastolic blood pressure $>90 \mathrm{~mm} \mathrm{Hg}$.
A rise in the systolic blood pressure of $30 \mathrm{~mm} \mathrm{Hg}$ or a rise in the diastolic blood pressure of $15 \mathrm{~mm} \mathrm{Hg}$, at least 4 hours apart or a single diastolic blood pressure $>110 \mathrm{~mm}$ $\mathrm{Hg}$ is also considered as hypertension with proteinuria of at least ' $1+$ ' or $1 \mathrm{~g} / \mathrm{L}$ on dipstick.

\section{Statistical analysis}

The statistical software package SPSS 16.0 for Windows was used for the analysis of the data. Goodness of fit test was conducted to check for the significance of independent variables against decision variable. The method applied is phi and Cramer's V method (chisquare test using crosstab). The categorical variables are given integer values and for quantitative variables statistical values are considered. For the above test the significance level was at 0.05 .

\section{RESULTS}

The patients who developed pre-eclampsia were grouped as preeclampsia group and the rest of the patients who remained normotensive till delivery were grouped as control group. The factors taken for analysis were age distribution, obstetric score, Body Mass Index and the components of lipid profile. Mean + SD of all variables of interest were determined for preeclampsia cohort and for normal cohort separately and difference was tested by t test.

Table 1: Maternal characteristics in preeclampsia and control groups.

\begin{tabular}{|c|c|c|c|c|c|}
\hline & & Preeclampsia group, $(\mathrm{N}=54)$ & Control group $(\mathrm{N}=146)$ & P value & Significance \\
\hline Age & & $27.2 \pm 4.9$ & $28.13 \pm 4.7$ & 0.680 & Not significant \\
\hline BMI & & $28.0 \pm 3.05$ & $25.5 \pm 2.87$ & 0.039 & Significant \\
\hline \multirow{2}{*}{ Parity } & Primi & $32(59.25 \%)$ & $61(41.78 \%)$ & \multirow{2}{*}{0.028} & \multirow{2}{*}{ Significant } \\
\hline & Multi & $22(40.74 \%)$ & $85(58.21 \%)$ & & \\
\hline \multirow{3}{*}{$\begin{array}{l}\text { Socioeconomic } \\
\text { status }\end{array}$} & I & $28(51.85 \%)$ & $68(46.57 \%)$ & \multirow{3}{*}{0.582} & \multirow{3}{*}{ Not significant } \\
\hline & II & $14(25.92 \%)$ & $49(33.56 \%)$ & & \\
\hline & III & $3(5.55 \%)$ & $12(8.21 \%)$ & & \\
\hline
\end{tabular}

Table 2: Serum lipid profile among preeclampsia and control groups.

\begin{tabular}{|lllll|}
\hline Serum lipid & Preeclampsia group & Control group & P value & Significance \\
\hline Total cholesterol & $240.24 \pm 46.63$ & $186.10 \pm 28.02$ & 0.002 & Significant \\
\hline Triglycerides & $291.95 \pm 82.334$ & $166.78 \pm 48.83$ & 0.00 & Significant \\
\hline LDL & $140.43 \pm 36.92$ & $94.6 \pm 24.5$ & 0.00 & Significant \\
\hline VLDL & $64.48 \pm 15.76$ & $33.54 \pm 9.38$ & 0.00 & Significant \\
\hline HDL & $47.49 \pm 4.40$ & $52.11 \pm 8.918$ & 0.002 & Significant \\
\hline
\end{tabular}

The predictive values of the individual components of lipid profile were analysed using ROC curve.

There is no statistical significance between the preeclampsia group and control group with respect to age distribution. Mean age of the patients in preeclampsia group $27.2 \pm 3.05$ and the patients in the control group were $28.13 \pm 4.7$. About $59.25 \%$ of the patients in preeclampsia group and $41.78 \%$ of the patients in the control group were primigravida. About $51.85 \%$ of the patients in preeclampsia group and $46.57 \%$ of the patients in the control group belongs to upper middle group, 
$25.92 \%$ of preeclampsia group and $33.65 \%$ of control group belongs to lower middle group, $5.55 \%$ of preeclampsia group and $8.21 \%$ of control group belongs to upper lower group of socio economic classification according to Kuppuswamy classification. The Mean BMI of preeclampsia group was $28.0 \pm 3.05$ while that of the control group was $25.5 \pm 2.87$. This clearly shows that the preeclampsia group had higher BMI than their controls.

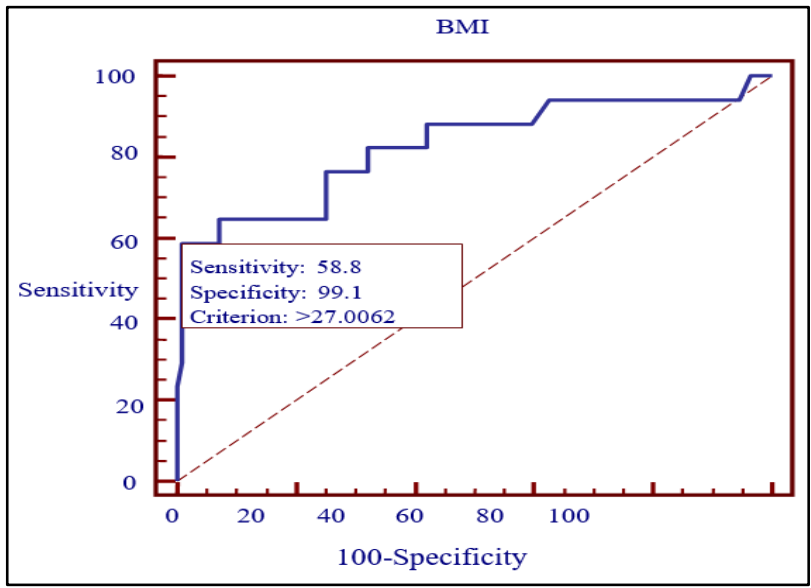

Figure 1: Area under the ROC curve for $\mathrm{BMI}$ is 0.828 .

Mean total cholesterol in Preeclampsia was $240.24 \pm 46.63$ $\mathrm{mg} / \mathrm{dl}$ and normal pregnancy was $186.10 \pm 28.02 \mathrm{mg} / \mathrm{dl}$. Mean HDL in preeclampsia was $47.49 \pm 4.40 \mathrm{mg} / \mathrm{dl}$ and normal pregnancy was $52.11 \pm 8.918 \mathrm{mg} / \mathrm{dl}$. Mean LDL in preeclampsia was $140.43 \pm 36.92 \mathrm{mg} / \mathrm{dl}$ and normal pregnancy was $94.6 \pm 24.5 \mathrm{mg} / \mathrm{dl}$. Mean VLDL in preeclampsia was $64.48 \pm 15.76 \mathrm{mg} / \mathrm{dl}$ and in normal pregnancy was $33.54 \pm 9.38 \mathrm{mg} / \mathrm{dl}$, Mean Triglycerides in preeclampsia was $291.95 \pm 82.33 \mathrm{mg} / \mathrm{dl}$ and normal pregnancy was $166.78 \pm 48.83 \mathrm{mg} / \mathrm{dl}$. Total cholesterol, Low density lipoprotein, very low-density lipoprotein, triglycerides were increased in preeclampsia when compared to normal pregnancy, which is statistically significant.

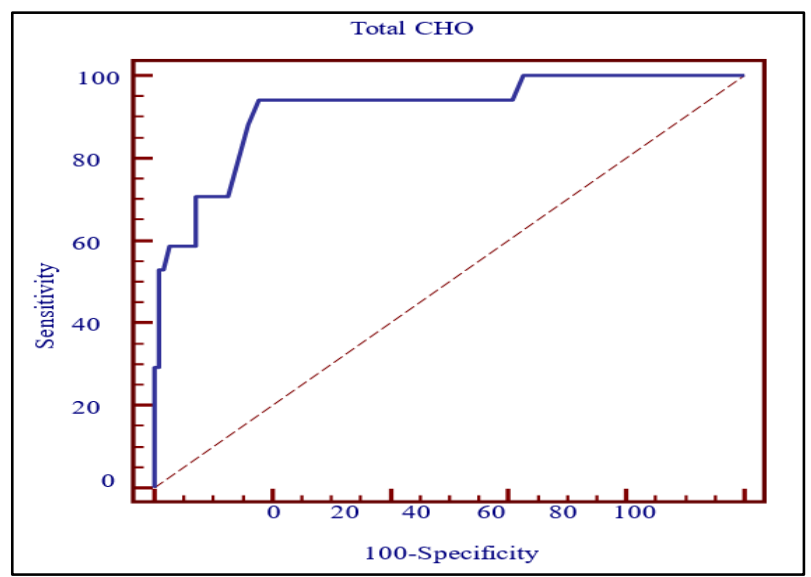

Figure 2: Area under the ROC curve for total $\mathrm{CHO}$ is 0.91 .
Receiver Operating Characteristic (ROC) Curve was used to test whether the selected lipid parameters predicted the occurrence of preeclampsia. The accuracy of the test is determined from are under the curve. If area under the curve is $0.90-1$ then the accuracy is excellent, and if it is 0.80-0.90 then the accuracy is good. Area under the ROC curve for BMI is 0.828 . On testing Total cholesterol as a predictor area under the ROC curve for Total $\mathrm{CHO}$ is 0.91 with Sensitivity-94.12\%, Specificity-82.14\% and Criterion $>200 \mathrm{mg} \%$.

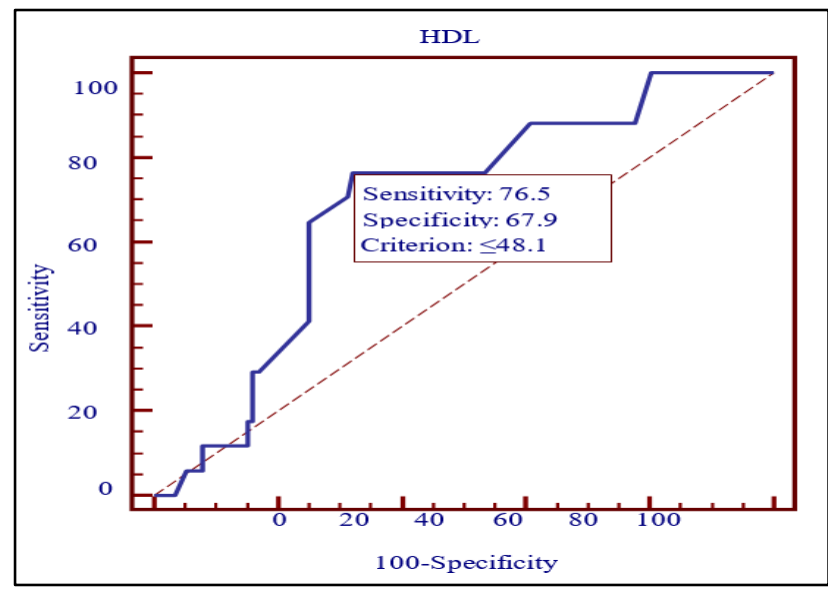

Figure 3: Area under the ROC curve for HDL is 0.68 .

On testing HDL as a predictor area under the ROC curve for HDL is 0.68 with Sensitivity $76.5 \%$, Specificity $67.9 \%$ and Criterion $<48.1 \mathrm{mg} \%$.

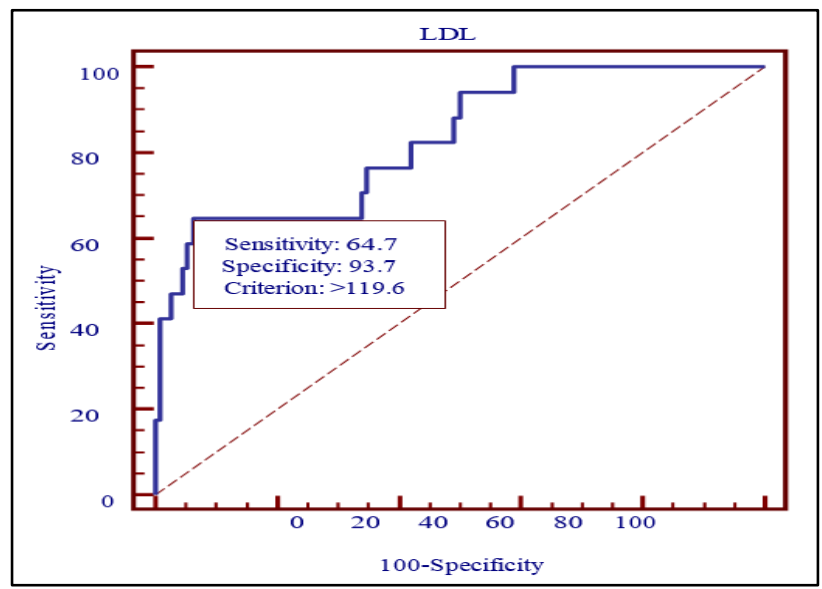

Figure 4: Area under the ROC curve for LDL is 0.83 .

On testing area under the ROC curve for LDL is 0.83 with Sensitivity $64.7 \%$, Specificity $93.7 \%$ and Criterion $>119.6 \mathrm{mg} \%$. On testing area under the ROC curve for VLDL is 0.91 with Sensitivity $88.2 \%$, Specificity $97.3 \%$ and Criterion $>48 \mathrm{mg} \%$.

On testing area under the ROC curve for TGL is 0.91 with Sensitivity $88.2 \%$, Specificity $97.3 \%$ and Criterion $>240 \mathrm{mg} \%$. 


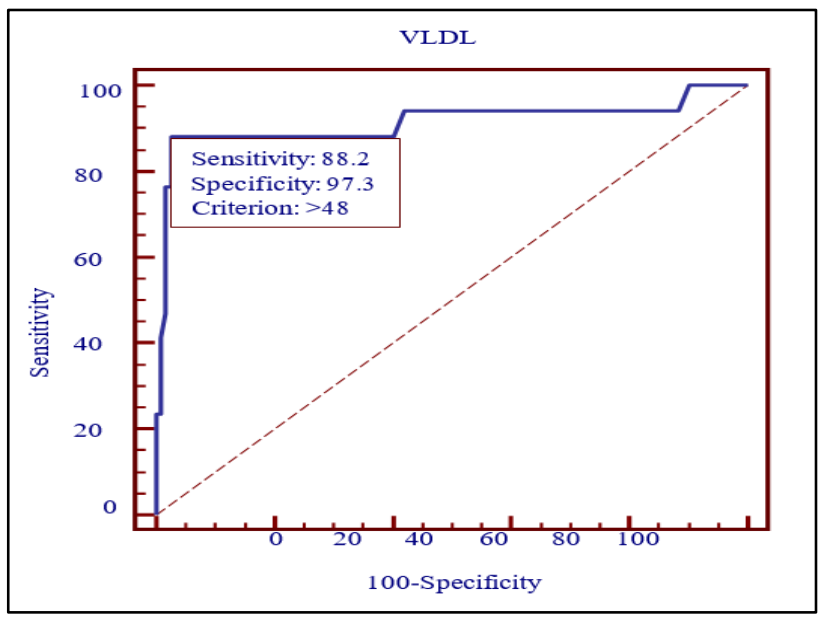

Figure 5: Area under the ROC curve for VLDL is 0.91 .

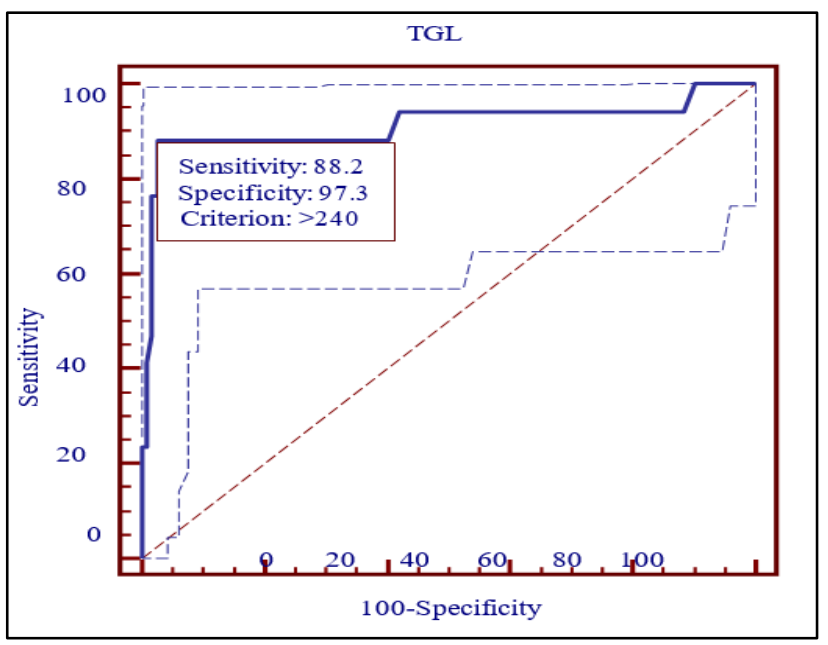

Figure 6: Area under the ROC curve for TGL is 0.91 .

\section{DISCUSSION}

Present study included 200 pregnant women; recruited from patients attending antenatal OP department. 54 patients developed preeclampsia and were grouped as the preeclampsia group and the remaining 146 pregnant women who were normal were taken as controls.

Vidyabati RK et al shows that there is hypertriglyceridemia among the patients who subsequently developed preeclampsia and total cholesterol, LDL, VLDL levels were also higher in preeclampsia women which was similar to present study. ${ }^{19}$ But the mean value of HDL for both the groups were similar in their study. In our study the level of HDL was lower in preeclampsia group.

Ray et al showed that the mean triglyceride concentration was raised among preeclampsia cases than among normotensive pregnant women and there exists a positive relation between higher $\mathrm{BMI}$ and increased risk of preeclampsia. ${ }^{20}$ In present study also, the patients who subsequently developed preeclampsia had higher body mass index than the pregnant women who remained normotensive and mean triglyceride were higher in preeclampsia group than controls.

Hubel $\mathrm{C}$ et al in their study showed that triglycerides and free fatty acids are raised in preeclampsia. ${ }^{21}$ Malondialdehyde, a lipid peroxidation metabolite causes endothelial dysfunction by its interaction. But the interaction or effects of this metabolite is not included in our study.

Higher body mass index, impaired (or) abnormal glucose tolerance and chronic hypertension the major features of metabolic syndrome are positively correlated with preeclamspsia in many studies.

VanDen Elzen $\mathrm{HJ}$ et al study showed that second trimester serum total cholesterol if higher was significantly associated with the risk of preeclampsia, results similar to present study. ${ }^{22}$

Basu A et al studied that early in pregnancy increased cholesterol rich lipoproteins were associated with subsequent preeclampsia similar to present study. ${ }^{23}$

Bodnar et al shows irrespective of the obstetric score women with preeclampsia had higher BMI during pregnancy compared to normotensive pregnancies. ${ }^{24}$

Sattar et al showed that the increased level of cholesterol and TGL in preeclamptic women. ${ }^{25}$ In present study women who developed preeclampsia had a higher TGL even before its development.

Lorentzen et al studied the correlation between raised sub fraction of lipoprotein and new onset proteinuric hypertension in pregnancy. ${ }^{26}$

In present study lipoprotein sub fraction were not studied. Further studies are required to determine the effects of lipoprotein sub fraction in pregnancy.

Anceshchi et al found altered ratio of cholesterol to phospholipids in the membrane of RBC in patients with preeclampsia. ${ }^{27}$ The studies of membrane phospholipids were not included in our study.

Present study similar to that by Murai JT et al shows significant raised levels of TGL in preeclamptic women. ${ }^{28}$ When variables with statistical significance were put in to binary logistic regression model, taking development of preeclampsia as dependent variable, TGL was most significant.

Wolf $\mathrm{M}$, et al studied the relationship of obesity with inflammation in the development of preeclampsia concluding increased BMI is a significant risk factor for developing dyslipidemia and preeclampsia similar to our study. ${ }^{29}$ 
The ROC curves for total Cholesterol, HDL, VLDL, TGL, LDL for their role as predictors shows that TGL has maximum area under the curve, revealing that TGL is the most efficient predictor among the components of lipid profile.

Edwards LE et al showed that there exists correlation between obesity and TGL levels. ${ }^{30}$ Increase in BMI increases TGL levels which in turn puts the patient at risk for developing preeclampsia.

Thus, pre pregnant weight reduction and life style modification may help in reducing the occurrence of preeclampsia. $^{31}$

Further studies are necessary to establish the role of pre pregnant weight reduction and to find out the whether this would help in reducing the incidence of preeclampsia. $^{32}$

\section{CONCLUSION}

After analysing and comparing the results between the preeclampsia cohort and normal cohort it was concluded that

- The pre-pregnant BMI was higher among the patients who developed preeclampsia than normotensive counterparts.

- The study cohort had a higher total cholesterol, triglyceride, low density lipoprotein, very lowdensity lipoprotein levels.

- The preeclampsia cohort also had a lower HDL level.

- Thus, there exists a positive correlation between dyslipidemia and development of preeclampsia.

- Therefore, abnormal lipid profile before 20 weeks is a very good predictor of preeclampsia development.

Thus, it may be concluded that, detecting dyslipidemia before 20 weeks of gestation would help us to recognise pregnancies at high risk for preeclampsia even before the clinical syndrome.

Early recognition, would help us in offering better surveillance to detect and treat the disease earlier for a better maternal and perinatal outcome.

Given that the raised triglyceridemia as a feature of the insulin resistance syndrome; interventional studies are required to find out whether pre-pregnancy weight reduction can lower the risk of preeclampsia.

The determination of insulin levels, inflammatory markers in early pregnancy and then followed by a thorough assessment of the outcome through a large cohort study, may help in addressing the role of metabolic syndrome in causation of preeclampsia.

Funding: No funding sources Conflict of interest: None declared
Ethical approval: The study was approved by the Institutional Ethics Committee

\section{REFERENCES}

1. Repke JT, Robinson JN. The prevention and management of pre-eclampsia and eclampsia. Int $\mathbf{J}$ Gynaecol Obstet. 1998;62:1-9.

2. Sharma JB, Sharma A, Bahadur A, Vimala N, Satyam A, Mittal, S. Oxidative stressmarkers and antioxidant levels in normal pregnancy and preeclampsia. Int J Gynaecol Obstet. 2006;94:23-7.

3. Berg CJ, Chang J, Callaghan Wm, et al. Pregnancy related mortality in united states 1991-1997. Obstet Gynecol. 2003;101:289.

4. Wiznitzer A, Mayer A, Novack V, Sheiner E, Gilutz $\mathrm{H}$, Malhotra A, et al. Association of lipid levels during gestation with preeclampsia and gestational diabetes mellitus: A population-based study. Am J Obstet Gynecol. 2009;201:482.e1-e8.

5. El-Mazny A, Abou-Salem N, El-Sherbiny W, ElMazny A. Insulin resistance, dyslipidemia, and metabolic syndrome in women with polycystic ovary syndrome. Int J Gynaecol Obstet. 2010;109:239-41.

6. Mankuta D, Elami-Suzin M, Elhayani A, Vinker S. Lipid profile in consecutive pregnancies. Lipids Health Dis. 2010;9:58.

7. Llurba E, Casals E, Domínguez C, Delgado J, Mercadé I, Crispi F, et al. Atherogenic lipoprotein subfraction profile in preeclamptic women with and without high triglycerides: Different pathophysiologic subsets in preeclampsia. Metabolism. 2005;54:1504-9.

8. Roberts JM, Gammill H. Insulin resistance in preeclampsia. Hypertension. 2006;47:341-2.

9. Catov JM, Bodnar LM, Kip KE, Hubel C, Ness RB, Harger G, et al. Early pregnancy lipid concentrations and spontaneous preterm birth. Am J Obstet Gynecol. 2007;197:610.e1-e7.

10. Ozdemir O, Coskun A, Arikan DC, Kiran G, Guven MA, Kilinc M. To evaluate role of lipid profil in the etiopathogenesis of mild and severe preeclampsia. Prenatal J. 2008;16:75-81.

11. El-Mazny A, Abou-Salem N, El-Sherbiny W, ElMazny A. Insulin resistance, dyslipidemia, and metabolic syndrome in women with polycystic ovary syndrome. Int J Gynaecol Obstet. 2010;109:239-41.

12. Roberts JM. Preeclampsia: What we know and what we do not know. Semin Perinatol. 2000;24:24-28.

13. Hershkovitz R, de Swiet M, Kingdom J. Midtrimester placentation assessment in high-risk pregnancies using maternal serum screening and uterine artery Doppler. Hypertens Pregnancy. 2005;24:273-80.

14. Zhou Y, Damsky CH, Fisher SJ: Preeclampsia is associated with failure of human cytotrophoblasts to mimic a vascular adhesion phenotype. One cause of defective endovascular invasion in this syndrome? J Clin Invest. 1997;99:2152-64. 
15. Carr DB, McDonald GB, Brateng D, Desai M, Thach CT, Easterling TR. The relationship between hemodynamics and inflammatory activation in women at risk for preeclampsia. Obstet Gynecol. 2001;98:1109-16.

16. Lim KH, Zhou Y, Janatpour M, McMaster M, Bass $\mathrm{K}$, Chun $\mathrm{SH}$ et al. Human cytotrophoblast differentiation/invasion is abnormal in preeclampsia. Am J Pathol. 1997;151:1809-18.

17. Bosio PM, McKenna PJ, Conroy R, O'Herlihy C: Maternal central hemodynamics in hypertensive disorders of pregnancy. Obstet Gynecol. 1999;94:978-984.

18. Danielson LA, Conrad KP: Acute blockade of nitric oxide synthase inhibits renal vasodilation and hyperfiltration during pregnancy in chronically instrumented conscious rats. $\mathbf{J}$ Clin Invest. 1995;96:482-90.

19. Vidyabati RK, Davina H, Singh NK, Singh WG. Serum beta hCG and lipid profile in early second trimester as a predictor of pregnancy induced hypertension. J Obstet Gynecol India. 2010;60(1).

20. JG Ray, P Diamond, P singh G, Bell C. Brief overview of maternal triglycerides as a risk of preeclampsia. Br J Obstet Gynecel. 2006;113(4):37986.

21. Hubel CA, Lyall F, Weissfeld L, Gandley RE, Roberts JM. Small low density lipoproteins and vascular cell adhesion molecule-1 are increased in association with hyperlipidemia in pregnancy. Metab Clin Experiment. 1998;47(10):1281-8.

22. Van Den Elzen HJ, Wladimroff JW, Cohen Overbeek TE, De Vruijn AJ, Grobbee DE. Serum lipids in early pregnancy and risk of Preeclampsia BJOG. 1996;103(2):170-22.

23. Basu A, Alaupovic P, Wu M, Jenkins AJ, Yu Y, Nankervis AJ et al. Plasma lipoproteins and preeclampsia in women with type 1 diabets: a prospective study. J Clini Endocrinol Metab. March 2012;97(5):1752-62.

24. Bodnar LM, Ness RB, Markovic N, Roberts JM. The risk of preeclampsia rises with increasing prepregnancy body mass index. Ann Epidemiol. 2005 Aug;15(7):475-82.

25. Sattar N, Bendomir A, Berry C, Shepherd J, Greer IA, Packard CJ. Lipoprotein subfraction concentrations in preeclampsia: pathogenic parallels to atherosclerosis. Obstet Gynecol. 1997;89(3):4038.

26. Lorentzen B, Henriksen T. Plasma lipids and vascular dysfunction in preeclampsia. Semin reprod Endocrinol. 1998;16(1):33-9

27. Anceschi MM, Coata G, Cosmi EV, Gaiti A, Trovarelli GF, RENZO G. Erythrocyte membrane composition in pregnancy-induced hypertension: Evidence for an altered lipid profile. BJOG: An Int J Obstet Gynecol. 1992 Jun 1;99(6):503-7.

28. Murai JT, Muzykanskiy E, Taylor RN. Maternal and fetal modulators of lipid metabolism correlate with the development of preeclampsia. Metabolism. 1997;46:963-7.

29. Wolf M, Kettyle E, Sandler L, Ecker JL, Roberts J, Thadhani R. Obesity and preeclampsia: the potential role of inflammation. Obstet Gynaecol. 2001;98:75762.

30. Edwards LE, Hellerstedt WL, Alton IR, Story M, Himes JH. Pregnancy complications and birth outcomes in obese and normal weight women: effects of gestational weight change. Obstet Gynecol. 1996;87:389-94.

31. Steinfeld JD, Valentine S, Lerer T, Ingardia CJ, Wax JR, Curry SL. Obesity-related complications of pregnancy vary by race. J Matern Fetal Med. 2000;9:238-41.

32. Gifford RW, August PA, Cunningham G. Report of the National High Blood Pressure Education Program Working Group on high blood pressure in pregnancy. Am J Obstet Gynecol. 2000;183:S1-S22.

Cite this article as: Kanmani K, Subramanian S. Association of dyslipidemia in second trimester of pregnancy with preeclampsia. Int J Reprod Contracept Obstet Gynecol 2018;7:435-41. 